\title{
Shelf-Life of Pumpkin Fruit Slices, Flour and Blended Products
}

\author{
Jedidah Wanjiku Kiharason ${ }^{1}$, Dorcas Khasungu Isutsa ${ }^{2,3}$, * \\ ${ }^{1}$ Department of Environmental Studies and Resources Development, Chuka University, Chuka, Kenya \\ ${ }^{2}$ Department of Plant Sciences, Chuka University, Chuka, Kenya \\ ${ }^{3}$ Department of Horticulture, Egerton University, Egerton, Kenya
}

Email address:

dorcaski@yahoo.com (D. K. Isutsa)

${ }^{*}$ Corresponding author

\section{To cite this article:}

Jedidah Wanjiku Kiharason, Dorcas Khasungu Isutsa. Shelf-Life of Pumpkin Fruit Slices, Flour and Blended Products. International Journal of Food Science and Biotechnology. Vol. 4, No. 1, 2019, pp. 14-25. doi: 10.11648/j.ijfsb.20190401.13

Received: January 20, 2019; Accepted: March 17, 2019; Published: April 10, 2019

\begin{abstract}
Pumpkin has high potential of generating income and overcoming food insecurity. Today's consumer looks upon the food industry to provide healthy, attractive convenience products that remain wholesome for long. However, spoilage of horticultural produce results due to improper handling and microbial attack. Microbial spoilage is the major factor limiting shelf-life of fresh produce and processed products. It arises from improper handling and spore contamination, leading to economic loss. The objective of the present study was to determine whether shelf-life of value-added pumpkin products could be prolonged by wrapping, drying, or processing. The study used products in three experiments: (1) pumpkin fresh fruit (presented as whole, half slices or quarter slices plus or minus clear shrink wrap); (2) pure flour (dried using oven, enhanced solar, or open sun); and (3) bakery products (cake, cookies, scones, mandazi, bread, porridge, chapatti or irio blended with $0 \%$, $5 \%, 20 \%, 50 \%$ or $90 \%$ pumpkin flour). All experiments were conducted in completely randomized design, replicated four times and repeated once. Pooled average data values were subjected to analysis of variance and significantly different means were separated using the least significantly difference test at $\alpha=0.05$. Plate Count Agar and Potato Dextrose Agar were used to determine total viable counts and fungi, respectively, on pumpkin fresh fruit, dried flour and blended products, while MacConkey Agar was used to assess enteric bacteria in dried flour and blended products. Results showed significant differences $(P<0.0001)$ in number of days taken for the tested samples to get spoilt. Slicing fruit drastically reduced shelf-life from 142 days to about 3 to 5 days. There were significant differences $(P<0.0001)$ in shelf-life of flour from the three drying methods. Enhanced solar dried flour had longest shelf-life of 11.5 months. Bacilli were the dominant bacteria in fresh fruit slices, while flour had bacilli and cocci, which were also dominant in blended products. Significant difference $(P<0.0001)$ occurred in moisture content of cake, mandazi and scones with various flour-blending levels. Cookies had the longest shelf-life of 64 days, while irio, chapatti and porridge got spoilt after two days. Significant differences occurred in microbial counts of the various flour-blended products throughout the storage periods. Baked products with up to $20 \%$ pumpkin flour-blend had great potential of remaining wholesome for longest storage period and hence are recommended for adoption.
\end{abstract}

Keywords: Fortification, Fruit Processing, Perishable Produce, Postharvest Loss, Storage Time, Value Addition

\section{Introduction}

Farm fresh produce is very sensitive to microbial contamination and therefore it should be dried or frozen to prolong shelf. Many fruits have nearly ideal conditions for growth of most microorganisms in their nutrient-rich and near neutral $\mathrm{pH}$ internal tissues. Uncut fruit is covered by an outer protective epidermis typically with natural waxy cuticle layer containing the polymer cutin [1]. Once the layer is destroyed by bruising or slicing the fruit, water loss and eventual spoilage ensue. Visual microbial growth on the fruit has been used as a main criterion to determine shelf-life of pieces stored under controlled atmosphere conditions [2]. Water-soaked appearance is common in most fresh produce. Microbial spoilage results in $30 \%-50 \%$ shrinkage of freshly 
cut fruits. It has been used by quality assurance advocates as the objective indicator of quality failure for more than $50 \%$ of fresh-cut vegetables and almost $100 \%$ of fresh-cut fruits [3].

The magnitude of post-harvest losses in fresh fruits and vegetables is estimated to range from $5 \%$ to $25 \%$ in developed countries and $20 \%$ to $50 \%$ in developing countries. In some African countries, the figure can rise up to $50 \%$ for very perishable foods such as fruits and vegetables. Losses occur in the field, during transportation, storage and processing. Insects, bacteria and fungi are often responsible for severe loss of nutritive value in food. When bacteria and fungi develop on produce, unfavourable chemical changes occur. Some fungi produce carcinogenic toxins rendering food unsuitable for human or animal consumption [4]. Spoilage microorganisms exploit the host using extracellular lytic enzymes that degrade the polymers to release water and other constituents. Fungi produce diverse and greater amounts of extracellular depolymerases, which successfully attack and spoil fruits and vegetables [5]. Processing can transform perishable produce into stable foods with long shelf-life, thereby aiding transportation and distribution [6]. Drying removes moisture to prevent microbial spoilage [7, 8].

Pumpkin fruits are used widely in most African countries for their food value. The species Cucurbita moschata is cultivated in almost all countries of tropical Africa, but is more important in Southern Africa than in Eastern and Western Africa [9]. Pumpkin has been recommended as a traditional food crop with high potential to overcome undernourishment and food poverty $[10,11]$, yet very little has been done to generate income from it [12]. In East Africa, pumpkin is among many crops facing poor consumption in urban centers where dwellers purchase processed food for convenience [6].

Today's consumer, whose lifestyle is continually changing, counts on the food industry to prepare healthy, convenient products with reduced saturated fats, cholesterol, sodium and calories [13-14]. The food industry majorly seeks to develop food products with attractive colour $[15,16]$, and extending the period during which food remains wholesome. Preservation techniques used include inhibition of microbial or biochemical changes to allow time for distribution, sale and home storage $[13,17]$. Pumpkin fruit is used to substitute wheat flour in bakery products and soups [16]. It is popular due to its attractive deep-orange natural colour and high fiber, making it a healthy substitute $[14,16,18]$. Bakery products have become targets for fibre enrichment in European diets due to health concerns and decrease in white bread consumption in western societies [19].

Usually spoilage of baked bread is due to improper handling during cooling and packaging, when spores present in the atmosphere contaminate the bread, leading to spoilage [20]. Post-process contamination must therefore be prevented [21]. Microbiological spoilage is often the major factor limiting shelf-life of bakery products, leading to economic loss to manufacturers and consumers [22]. The most common bacteria causing spoilage of bakery products is Bacillus subtilis, whose spores are heat-resistant and remain active after cooking. The major source of bacillus contamination is the raw ingredients. This bacterium is responsible for ropey bread characterized by a pineapple-like odour. Later bread becomes discoloured, soft and sticky. Strict sanitary and good manufacturing practices should be applied to control the bacillus spores and their problems [23]. On the other hand, yeast causes visible growth on the surface of products. Long shelf-life of products enables a great variety of products to be stored [21]. This paper reports findings on effects of pumpkin fresh fruit slicing, drying into flour, as well as blending into processed products on shelf-life and microbial contamination.

\section{Materials and Methods}

\subsection{Pumpkin Fruit Shelf-life Determination}

The shelf-life of pumpkin fruit was determined by comparing the spoilage rate of whole fruit, fruit sliced into halves or quarters plus or minus wrapping using clear shrink wrap polythene. Shelf-life was assessed at two-day intervals by recording weight loss and number of days the samples remained with acceptable microbial load. Mature whole fruits were stored on a safe, cool and dry surface at room temperature. Changes were observed on monthly basis and recorded. Microbial growth was assessed at two-day intervals by inoculating samples on both general and specific media in Petri dishes. For bacterial and fungal growth, Plate Count Agar (PCA) and Potato Dextrose Agar (PDA) were used, respectively. One (1) gram was cut from each fruit sample. Before culturing was done, sterilization following standard procedures was done for all equipment, distilled water and media (Plate Count Agar/Standard Methods Agar: Plate Count HIMEDIA Ref. M091-500G LOT 00002787460, and Potato Dextrose Agar-Ref. M096-500G-LOT 0000279034). A total of $23 \mathrm{~g}$ of PCA was reconstituted in $1000 \mathrm{ml}$ sterile distilled water, heated to dissolve and then sterilized by autoclaving at $121^{\circ} \mathrm{C}$ and $100 \mathrm{kPa}$ for 15 minutes. It was then cooled in a water bath at $45^{\circ} \mathrm{C}$ to $50^{\circ} \mathrm{C}$. About $15 \mathrm{ml}$ of the media was dispensed into Petri dishes in a biosafety cabinet and left to set before inoculation. The same procedure was followed using $39 \mathrm{~g}$ of PDA. Before dispensing, PDA was acidified using tartaric acid at $1 \mathrm{ml}$ acid to $100 \mathrm{ml}$ media to inhibit bacterial growth.

Assessment of microbes in the samples was done by identification and recording following standard procedures. In this case, $1 \mathrm{~g}$ of sample was put in $90 \mathrm{ml}$ of sterile distilled water and mixed well. Serial dilutions of $10^{-1}, 10^{-2}$ and $10^{-3}$ were prepared and then spread plate technique applied for PDA and pour plate for PCA. The inocula were incubated at $37^{\circ} \mathrm{C}$ for 18 to 24 hours for PCA, while PDA the plates were set at room temperature for up to 48 hours before discarding. PCA indicated total viable count on fruit samples, while PDA was used to assess fungal and mould spoilage of fruit samples. 
Bacteria were stained for identification by preparing a smear fixed on a Bunsen burner flame. The stain was flooded with crystal violet solution on a staining rack for 60 seconds and then washed using distilled water. It was then flooded with iodine (mordant) for 30 seconds and washed. The smear was then bleached using acetone and washed instantly. It was then counter-stained using $10 \%$ cerbol fuschin for 30 seconds, washed, blot-dried, and examined under a microscope using x100 magnification. The microbial morphology was observed, and if the colour to the Gram reaction was pink or red, it identified Gram negative, while if blue or black colour, it identified Gram positive.

\subsection{Flour Quality and Shelf-life Determination}

Pumpkin fruit was dried using three different methods: Open Sun (OSD), Enhanced Solar (ESD), and Oven-Electric (OED), each with four replicates. Pumpkin flour was prepared by grinding dried pumpkin fruit pieces, using a Teflon-coated mill, and sieving to achieve uniform fine powder. To determine flour keeping quality, the moisture content was determined. A small $(1 \mathrm{~g})$ weight of powder in a crucible was heated in a dry oven at $105^{\circ} \mathrm{C}$ for 2 hours, then covered with aluminum foil and cooled in a desiccator for 1 hour. Percent moisture content was determined by calculating the difference between the weight $(\mathrm{g})$ of sample before and after heating, divided by sample weight ( $g$ ) before heating, multiplied by 100 .

Extraction rate of the flour from the different drying methods was also determined. Four replicates of dried fruit from each drying method were milled using a grinder, subjected to the same pulse and grinding period, until fine flour was achieved. The flour was weighed before passing through a sieve to attain fine uniform powder and weighed again. The extraction rate $(\%)$ of flour from the three drying methods was determined by calculating the difference between weight $(\mathrm{g})$ of flour before and after sieving, divided by weight of flour before sieving, multiplied by 100 .

The shelf-life of pumpkin flour from the three drying methods was determined by recording the number of days the flour remained at safe microbial levels. Before culturing, sterilization of all equipment, distilled water and media (PCA, PDA and MacConkey (MAC), was done following standard procedures. Microbial analysis included identification and enumeration of bacteria and presence of coliforms following standard procedures. Sample preparation, serial dilution and inoculation of samples were done as described for pumpkin fruit on PCA and PDA. MacConkey agar-HIMEDIA (Ref. M081-500G LOT 0000268460), a selective media for isolation of coliforms (enterics), was used to check the safety of the flour during the whole line of preparation up to just before laboratory analysis. PCA gave the total viable counts in the flour, while PDA was used to assess fungi, mould and fitness for use.
MacConkey inoculant was streaked onto the solidified media before incubation as for PCA. Staining of microbes from the culture was done as earlier described for pumpkin fruit.

\subsection{Blended Products'Shelf-life Determination}

Preparation of products for shelf-life determination was done following previously outlined recipes for each product [20]. Five market products, namely: cake, cookies, scones, mandazi, bread and three traditional ones (porridge, chapatti and irio) were prepared. To prevent contamination of products after preparation, they were immediately cooled and packaged inside a biosafety cabinet. New polythene bags were used for tight-sealing and packaging. Each product had four replicates, which aseptically packaged into smaller pieces at the same time. The smaller pieces were necessary because each replicate once opened for culturing would be discarded to eliminate contamination and compromising subsequent use. The packaged products were then arranged on a tray and kept on a counter in the laboratory at room temperature. Shelf-life determined by recording the number of days each product remained at safe microbial level. Methods used for sterilization, sample and media preparation and identification of microorganisms in the food products using PCA, PDA, MacConkey agar were as earlier described. However, homogenization of $1 \mathrm{~g}$ food sample in $9 \mathrm{ml}$ sterile distilled water in a test tube was done by crushing in a pestle and mortar while wrapped in a new unused polythene bag, followed by vigorous shaking.

\subsection{Data Analysis}

Data values were subjected to ANOVA using SAS version 9.3. Significant means were separated using the Least Significance Difference test at $\alpha=5 \%$.

\section{Results}

\subsection{Shelf-life of Pumpkin Fruit and Flour Samples}

Figure 1 shows observable changes on whole fruit at 1 day, $2^{\text {nd }}, 6^{\text {th }}$ and $7^{\text {th }}$ months postharvest. Observation on the fruit slices showed that the keeping quality drastically reduced, with deterioration starting a few days after storage. By day four, undesirable changes were evident and unwrapped slices had begun to develop mould, which spread all over the surface by day 6 . The half unwrapped slices took 3 to 4 days before getting spoilt, while the quarter-sliced pieces took 3 days. The wrapped slices were characterized by less mould, but had slimy surface under the wrapping. Half slices took 5 days, compared to 4 days for quarter slices to get spoilt. By day 6 all the slices (wrapped and unwrapped) were completely spoilt with fungal growth physically evident on entire surfaces (Figure 2; Plates 3 and 4). 


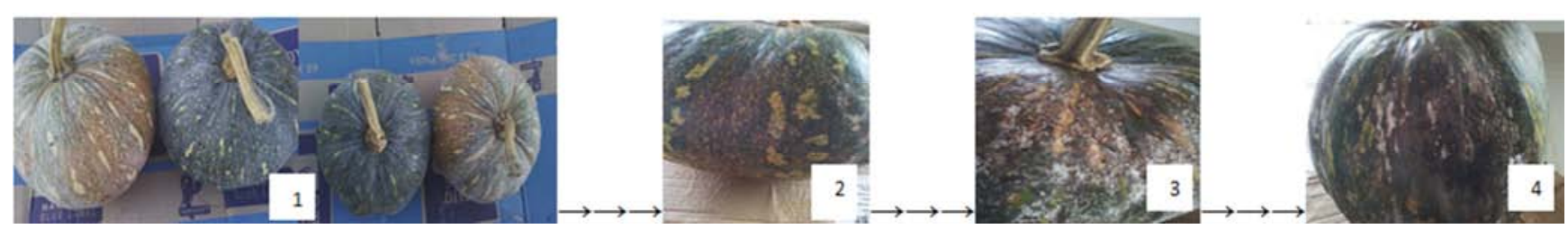

Figure 1. Observable changes on whole fruit over storage time. Plate 1: Whole fruit storage at day 1, Plate 2: $2^{\text {nd }}$ month; Plate 3: $6^{\text {th }}$ month; Plate 4: $7^{\text {th }}$ month in storage.
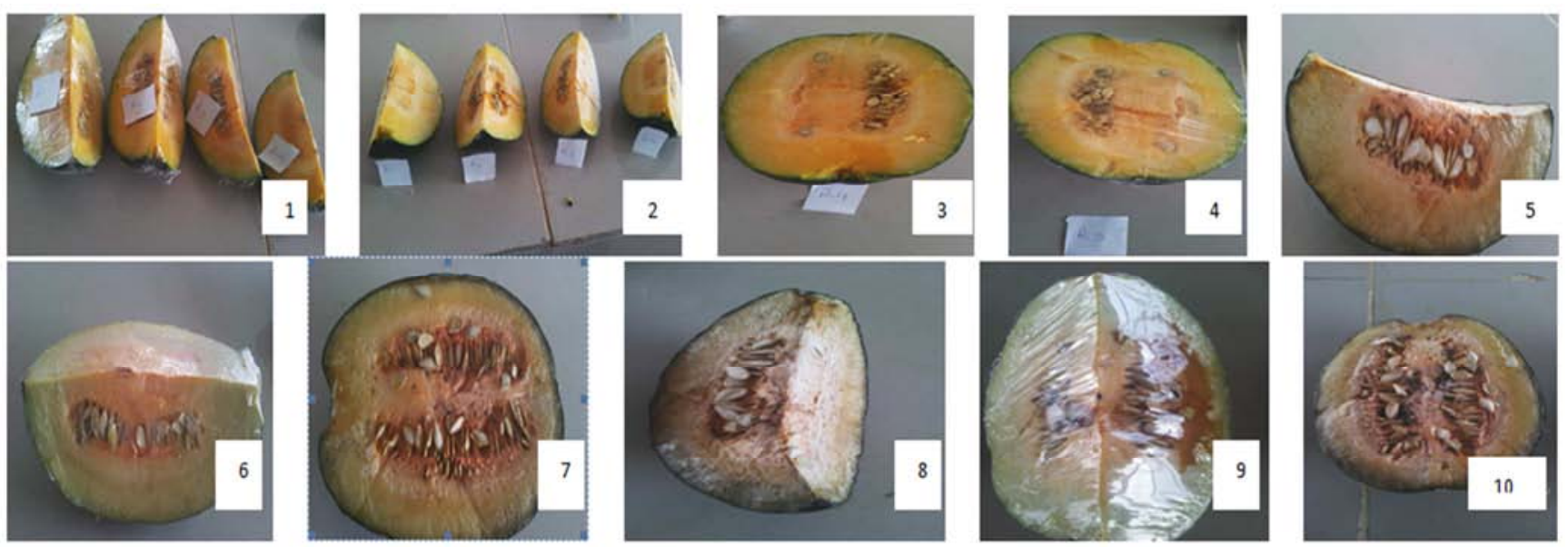

Figure 2. Visual changes on fruit slices. Plate 1: 1/4 slices replicate 1 to 4 wrapped (W) day 1; Plate 2: Fruit 1/4 slices replicate 1 to 4 unwrapped (UW) day 1; Plate 3: 1/2 slice UW day 1; Plate 4: 1/2 slice W day 1; Plate 5: 1/4 slice UW day 3; Plate 6: 1/4 slice $W$ day 3; Plate 7: 1/2 slice UW day 3; Plate 8: 1/4 slice UW day 6; Plate 9: 1/2 slice W day 6; Plate 10: $1 / 2$ slice UW day 6.

Changes in weight loss of fruit slices showed that the wrapped slices had the least rate of moisture loss, compared to the unwrapped ones (Figure 3). Table 1 shows the weight differences after every two days from day zero to day six. The results revealed significant differences $(P<0.0001)$ in weight loss among the quarter and half slices up to the sixth day post-slicing. The wrapped slices had much less total weight loss compared to unwrapped slices. Table 2 shows significant differences $(P<0.0001)$ in the number of days it took for whole fruit compared to sliced fruit to get spoilt. It took a much longer (142 days) for whole fruit to get spoilt, while spoilage among the fruit slices was not significantly different. Of all the slices, half wrapped took the longest (4.75 days) to get spoilt, while quarter unwrapped fruit slices took the fewest days to get spoilt.

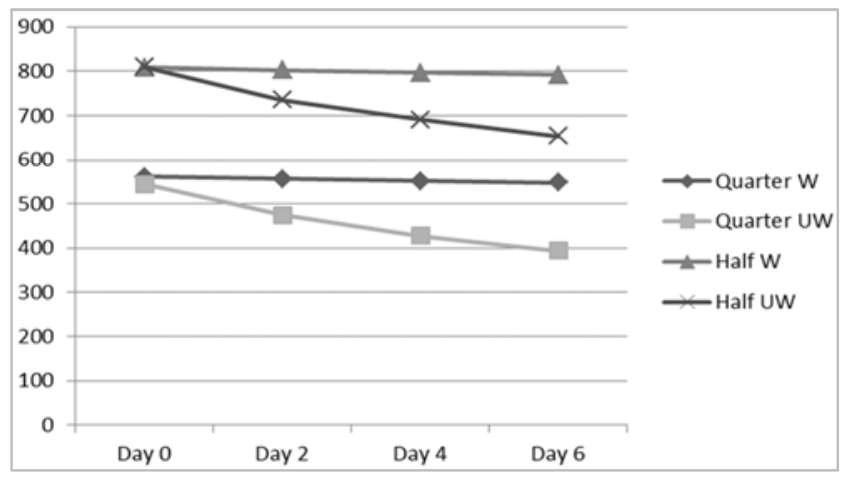

Figure 3. Weight loss of sliced and wrapped or unwrapped fruit slices.
Table 1. Means of weight loss in days for various fruit slices.

\begin{tabular}{llll}
\hline Presentation format & Day two & Day four & Day six \\
\hline Quarter wrapped & $5.01 \mathrm{~b} *$ & $4.12 \mathrm{~b}$ & $3.62 \mathrm{~b}$ \\
Quarter unwrapped & $73.12 \mathrm{a}$ & $42.38 \mathrm{a}$ & $34.51 \mathrm{a}$ \\
Half wrapped & $6.20 \mathrm{~b}$ & $5.12 \mathrm{~b}$ & $4.33 \mathrm{~b}$ \\
Half unwrapped & $74.37 \mathrm{a}$ & $44.59 \mathrm{a}$ & $35.66 \mathrm{a}$ \\
$P$-value & $<0.0001$ & $<0.0001$ & $<0.0001$ \\
$\mathrm{LSD}_{0.05}$ & 2.899 & 2.533 & 3.037 \\
\hline
\end{tabular}

* Means followed by the same letter within a column are not significantly different at $\alpha=0.05$.

Table 2. Days before spoilage of fruit slices.

\begin{tabular}{llll}
\hline Presentation format & Days & $\boldsymbol{P}$-value & LSD $_{0.05}$ \\
\hline Quarter wrapped & $4.25 \mathrm{~b}^{*}$ & $<0.0001$ & 26.129 \\
Quarter unwrapped & $3.00 \mathrm{~b}$ & & \\
Half wrapped & $4.75 \mathrm{~b}$ & & \\
Half unwrapped & $3.5 \mathrm{~b}$ & & \\
Whole fruit & $142.5 \mathrm{a}$ & & \\
\hline
\end{tabular}

*Means followed by the same letter within a column are not significantly different at $\alpha=0.05$.

\subsection{Microbial Assessment of Sliced Fruit}

Visual observations after 2 days of incubation showed overgrowth of bacteria (uncountable), as well as presence of many fungal colonies in all the fruit sample plates. The bacteria from the fruit samples were identified as Gram positive rods (bacilli) and cocci-bacilli (clostridium) (Figure 4; Plates 5 and 6). 

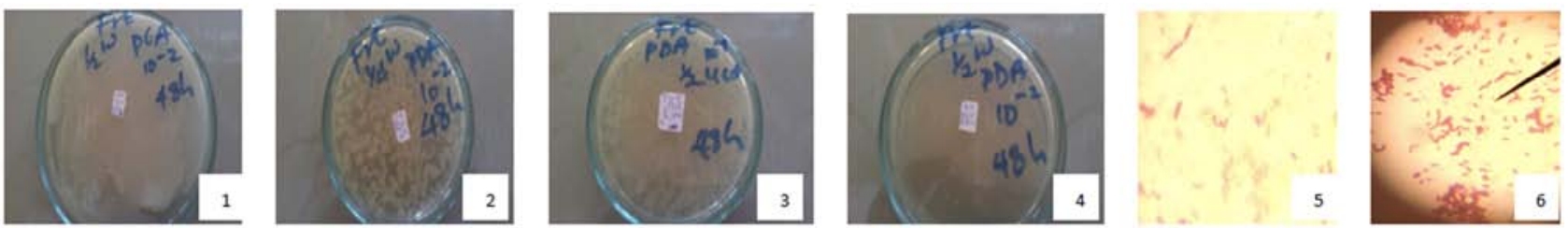

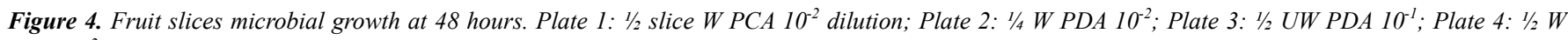
PDA 10 $0^{-2}$; Plate 5: Bacilli; Plate 6: Cocci-bacilli (Clostridium).

\subsection{Pumpkin Flour Quality and Shelf-life}

Results showed that moisture content (MC) ranged from $12.82 \%$ to $15.15 \%$, of which ESD had the lowest (Table 3). There was, however, no significant difference in the MC of pumpkin flour for the three drying methods. There was a significant difference $(P<0.0001)$ in the extraction rate $(\mathrm{ER})$ of flour for the three drying methods. Enhanced solar drying had the highest $(88.95 \%)$ extraction rate (Table 3). Total Viable Counts (TVC) in stored pumpkin flour of the three drying methods showed that OED flour took the shortest period of 6 months before exceeding safe microbial limit (Table 4). There was a significant difference $(P<0.0001)$ in shelf-life of flour for the three drying methods, where ESD flour had least moisture content and longest period of 11.5 months, while OED flour took 6.5 months. There were significant differences $(P<0.05)$ in the number of colony forming units (cfu/g) for the flours. Microbial growth (Figure
5) for ESD and OED flours had white round colonies, identified as Gram positive rods (bacilli), while OSD had medium-raised round citrus coloured colonies, identified as Gram positive cocci in chains (streptococci). Growth of fungi appeared in OED flour at the $7^{\text {th }}$ month, while the other flours did not show any. MacConkey tests were negative for all samples, thus there was no enteric bacteria present.

Table 3. Pumpkin flour quality characteristics.

\begin{tabular}{llll}
\hline Method & Average MC (\%) & Means of ER (\%) & $\begin{array}{l}\text { Means of shelf- } \\
\text { life (months) }\end{array}$ \\
\hline ESD & $12.82 \mathrm{a}^{*}$ & $88.95 \mathrm{a}^{*}$ & $11.5 \mathrm{a}^{*}$ \\
$\mathrm{OSD}$ & $14.91 \mathrm{a}$ & $77.40 \mathrm{~b}$ & $9.5 \mathrm{~b}$ \\
$\mathrm{OED}$ & $15.15 \mathrm{a}$ & $71.85 \mathrm{a}$ & $6.5 \mathrm{c}$ \\
$P$-value & 0.2552 & $<0.0001$ & $<0.0001$ \\
$\mathrm{LSD}_{0.05}$ & 3.1124 & 2.392 & 0.4502 \\
\hline
\end{tabular}

${ }^{*}$ Means followed by the same letter within a column are not significantly different at $\alpha=0.05$.

Table 4. Means of total viable counts in stored pumpkin flour.

\begin{tabular}{|c|c|c|c|c|c|c|c|c|}
\hline Method & 2 months & 6 months & 7 months & 8 months & 9 months & 10 months & 11 months & 12 months \\
\hline OSD & $517 \pm 35 a^{*}$ & $8450 \pm 750 b$ & $17050 \pm 737 b$ & $66500 \pm 3872 a$ & $79500 \pm 8346 a$ & $116250 \pm 13326 a$ & & \\
\hline ESD & $302 \pm 17 \mathrm{c}$ & $1450 \pm 208 b$ & $1725 \pm 170 b$ & $2400 \pm 336 b$ & $7700 \pm 1439 b$ & $15250 \pm 5737 b$ & $59700 \pm 24905$ & $144000 \pm 16633$ \\
\hline OED & $417 \pm 62 b$ & $76500 \pm 10246 a$ & $525000 \pm 77244 a$ & & & & & \\
\hline $\mathrm{LSD}_{0.05}$ & 71.804 & 10016 & 72291 & 6582.6 & 14521 & 16485 & & \\
\hline$P$-value & 0.0010 & $<0.0001$ & $<0.0001$ & $<0.0001$ & 0.0006 & 0.0003 & & \\
\hline
\end{tabular}

*Means followed by the same letter within a column are not significantly different at $\alpha=0.05$
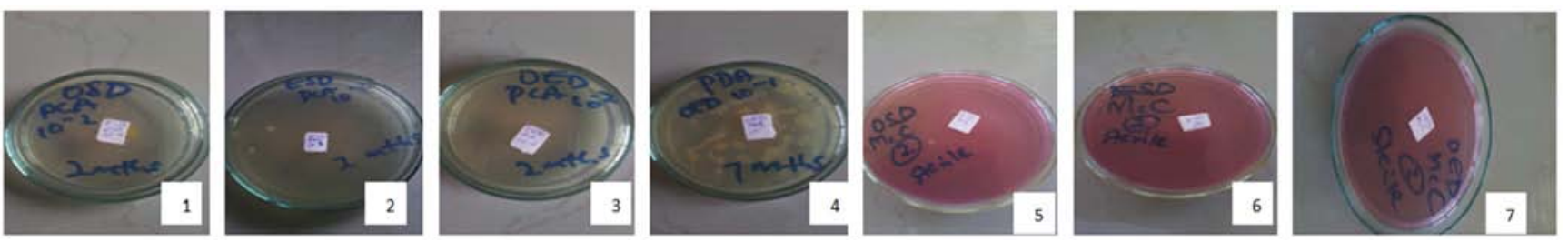

Figure 5. Observation of stored pumpkin fruit flour cultures. Plate 1: OSD flour PCA 10-2 at two months, Plate 2: ESD flour PCA 10-2 at 2 months, Plate 3: OED flour PCA $10^{-2}$ at 2 months, Plate 4: OED flour PDA 10 $10^{-1}$ at 7 months, Plate 5: OSD flour MAC sterile at 2 months, Plate 6: ESD flour MAC sterile at 2 months, Plate 7: OED flour MAC sterile at 2 months.

\subsection{Shelf-life of Pumpkin-Blended Products}

\subsubsection{Moisture Content of Products}

Moisture content revealed significant differences $(P<0.0001)$. Moisture content in levels 2 and 5 cake was higher, while moisture content in level 5 mandazi was lower than that of other flour-blending levels. In bread and scones, moisture levels increased with increase in pumpkin flour levels (Table 5). Cookies did not show significant differences $(P=0.246)$, although they had the lowest $6.5 \%$ to $9.0 \%$ moisture content in the five flour-blending levels.

\subsubsection{Shelf-life of Cookies}

The total viable counts (TVC) on day two ranged from 167 $\mathrm{cfu} / \mathrm{g}$ in level 1 to $312 \mathrm{cfu} / \mathrm{g}$ in level 3 (Table 6), which increased slowly every 48 hours. There were significant differences $(P<0.05)$ in the total viable counts among the various flour-blending levels across all days, with level 5 having highest microbial levels from day 10 to the end. Level 1 remained safe up to day 64, while level 5 took 60 days before getting spoilt. Cookies had irregular (amorphous) flatwhite colonies, which spread over the media. Identification 
revealed Gram positive long thick rods (bacilli) and clustered were observed in flour-blending level 4 on day 64 and in cocci (staphylococci) bacteria. Gram positive budding rods

flour-blending level 5 on day 62.

Table 5. Means of moisture content (\%) of pumpkin products at five blending levels.

\begin{tabular}{lllll}
\hline Level (\% pumpkin flour) & Cookies & Cake & Mandazi & Bread \\
\hline $1(0 \%)$ & $9.00 \mathrm{a}^{*}$ & $19.50 \mathrm{~d}$ & $26.00 \mathrm{ab}$ & $32.75 \mathrm{c}$ \\
$2(5 \%)$ & $8.00 \mathrm{ab}$ & $24.50 \mathrm{c}$ & $23.75 \mathrm{~b}$ & $34.25 \mathrm{~b}$ \\
$3(20 \%)$ & $7.25 \mathrm{ab}$ & $20.00 \mathrm{~d}$ & $26.75 \mathrm{a}$ & $33.25 \mathrm{bc}$ \\
$4(50 \%)$ & $8.00 \mathrm{ab}$ & $29.00 \mathrm{~b}$ & $25.75 \mathrm{ab}$ & $41.25 \mathrm{a}$ \\
$5(95 \%)$ & $6.50 \mathrm{~b}$ & $33.00 \mathrm{a}$ & $13.50 \mathrm{c}$ & $14.00 \mathrm{c}$ \\
$\mathrm{LSD}_{0.05}$ & 2.302 & 0.974 & 2.298 & $41.75 \mathrm{a}$ \\
$P$-value & 0.246 & $<0.0001$ & $<0.0001$ & $26.50 \mathrm{a}$ \\
\hline
\end{tabular}

*Means followed by the same letter within a column are not significantly different at $\alpha=0.05$.

Table 6. Means of total viable counts in stored cookies.

\begin{tabular}{|c|c|c|c|c|c|c|c|}
\hline Level & Day 2 & Day 10 & Day 30 & Day 60 & Day 62 & Day 64 & Day 66 \\
\hline $1(0 \%)$ & $00 \mathrm{e}^{*}$ & $207 \pm 9 c$ & $235 \pm 34 b$ & $700 \pm 81 b$ & $820 \pm 43 c$ & $937 \pm 35 c$ & $1450 \pm 191$ \\
\hline $2(5 \%)$ & $257 \pm 43 b$ & $425 \pm 95 b$ & $557 \pm 35 a$ & $775 \pm 50 \mathrm{a}$ & $922 \pm 49 b$ & $1275 \pm 250 b$ & \\
\hline $3(20 \%)$ & $312 \pm 15 \mathrm{a}$ & $495 \pm 26 a b$ & $562 \pm 17 \mathrm{a}$ & $757 \pm 40 \mathrm{a}$ & $787 \pm 25 \mathrm{c}$ & $1200 \pm 163 b$ & \\
\hline $4(50 \%)$ & $100 \pm 16 d$ & $227 \pm 21 \mathrm{c}$ & $262 \pm 17 b$ & $437 \pm 35 b$ & $957 \pm 20 \mathrm{~b}$ & $1500 \pm 216 a$ & \\
\hline $5(95 \%)$ & $212 \pm 18 \mathrm{c}$ & $500 \pm 21 a$ & $560 \pm 31 \mathrm{a}$ & $860 \pm 29 a$ & $112 \pm 95 \mathrm{a}$ & & \\
\hline $\mathrm{LSD}_{0.05}$ & 38.077 & 74.067 & 38.95 & 91.73 & 71.975 & 183.55 & \\
\hline
\end{tabular}

*Means followed by the same letter within a column are not significantly different at $\alpha=0.05$.
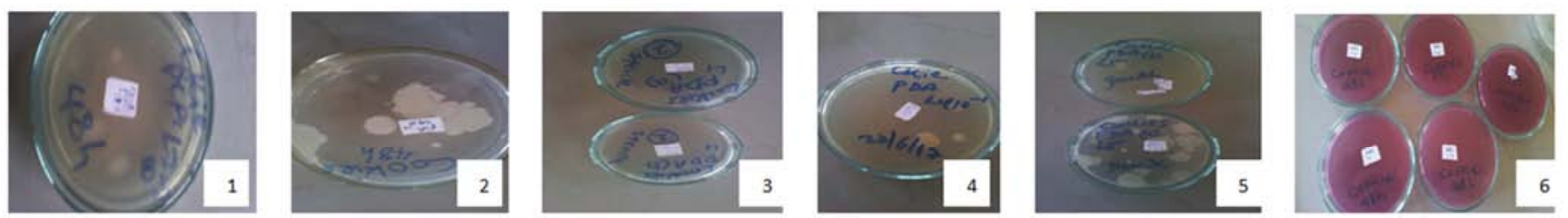

Figure 6. Appearance of PDA, PCA and MAC cultures of cookies. Plate 1: cookies level 2 PCA 10-3 dilution at 48 hrs, Plate 2: level 4 PCA 10-1 at 48 hrs, Plate 3: level 1 PDA 10-1 sterile at day 66, Plate 4: level 4 PDA 10-1 day 64, Plate 5: level 5 PDA 10-1, Plate 6: levels 1 to 5 MAC sterile at 48 hrs.

\subsubsection{Shelf-life of Cake}

Total viable count for cake showed that levels 4 and 5 remained within safe bacterial counts up to day 6 , while levels 1, 2 and 3 remained safe up to day 10 (Table 7). On days 2 and 4, significant differences occurred $(\mathrm{P}<0.0001)$ in the number of cfu/g among levels 1, 2 and 5, while levels 3 and 4 were not significantly different. The number of $\mathrm{cfu} / \mathrm{g}$ in levels 1,2 and 3 were significantly different $(\mathrm{P}<0.0001)$ on day 10 , with level 2 having the least cfu/g. On day 12 , levels 1 and 2 were beyond safe microbial counts, and significant differences existed $(\mathrm{P}=0.0065)$ in the $\mathrm{cfu} / \mathrm{g}$ of the two levels.
Visual observation for fungal growth was evident in level 5 on day 4 and hence the product was rendered unsafe. In levels 3 and 4, fungal growth was noted on day 8, while in levels 1 and 2, it occurred on day 12. Observation of the PCA plates of cake inoculants showed flat, irregular white colonies which were mucoid to touch. These were identified as Gram positive rods (bacilli) (Plate 2 Figure 7). MacConkey showed negative results for enteric bacteria, as was the case for cookies, while PDA tests showed growth on different days. Growth on the PDA was identified as Gram positive budding thick rods.

Table 7. Means of total viable counts in stored cake.

\begin{tabular}{lllllll}
\hline Level & Day 2 & Day 4 & Day 6 & Day 8 & Day 10 & Day 12 \\
\hline $1(0 \%)$ & $97 \pm 17 \mathrm{a}^{*}$ & $127 \pm 25 \mathrm{a}$ & $427 \pm 25 \mathrm{~b}$ & $700 \pm 141 \mathrm{c}$ & $817 \pm 35 \mathrm{~b}$ & $1125 \pm 189 \mathrm{~b}$ \\
$2(5 \%)$ & $42 \pm 18 \mathrm{~b}$ & $77 \pm 12 \mathrm{~b}$ & $300 \pm 81 \mathrm{ab}$ & $575 \pm 125 \mathrm{c}$ & $715 \pm 19 \mathrm{~b}$ & $1450 \pm 100 \mathrm{a}$ \\
$3(20 \%)$ & $10 \pm 8 \mathrm{c}$ & $22 \pm 9 \mathrm{c}$ & $275 \pm 12 \mathrm{a}$ & $800 \pm 12 \mathrm{c}$ & $800 \pm 170 \mathrm{a}$ & \\
$4(50 \%)$ & $12 \pm 5 \mathrm{c}$ & $37 \pm 17 \mathrm{c}$ & $417 \pm 17 \mathrm{ab}$ & $1600 \pm 432 \mathrm{~b}$ & & \\
$5(95 \%)$ & $62 \pm 17 \mathrm{~b}$ & $75 \pm 12 \mathrm{~b}$ & $400 \pm 182 \mathrm{ab}$ & $2225 \pm 386 \mathrm{a}$ & & \\
LSD $_{0.05}$ & 23.701 & 21.236 & 147.94 & 480.45 & 166.63 & 152.35 \\
$P$-value & $<0.0001$ & $<0.0001$ & 0.1315 & $<0.0001$ & $<0.0001$ & 0.0065 \\
\hline
\end{tabular}

*Means followed by the same letter within a column are not significantly different at $\alpha=0.05$. 

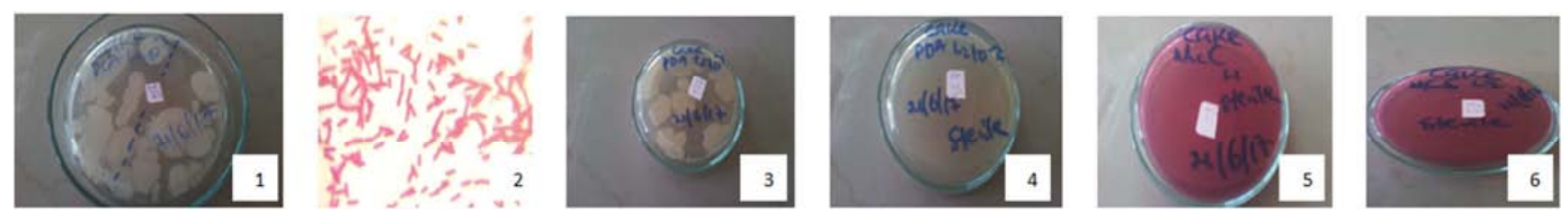

Figure 7. Appearance of PDA, PCA and MAC cultures of cake. Plate 1: level 4 PCA 10-3 on day 8, Plate 2: Bacilli, Plate 3: level 3 PDA 10-1 day 8, Plate 4: level 2 PDA 10-2 sterile at day 8, Plate 5: level 1 MAC sterile at day 8, Plate 6: level 2 MAC sterile at day 8.

\subsubsection{Shelf-life of Mandazi}

On day two, bacterial counts were lowest $(50 \mathrm{cfu} / \mathrm{g})$ for level 4 and highest for level $3(192 \mathrm{cfu} / \mathrm{g})$. There were significant differences $(P<0.0001)$ in the number of cfu/g for the various levels on day two. At spoilage (day six), the products had up to $12,000 \mathrm{cfu} / \mathrm{g}$. Safe bacterial levels in mandazi were noted up to day four, after which the products were rendered unsafe. Levels 4 and 5 were especially very high in TVC after day four (Table 8).

Mandazi cultures showed medium raised, round citrus coloured colonies (Plate 3, Figure 8), which were identified as Gram positive cocci in clusters (staphylococci bacteria). Selective culturing for enteric bacteria showed negative results in all plates, hence the products were safe. On days 2 and 4 , the PDA plates remained sterile, while day 6 was characterized by Gram positive budding rods in all plates.

Table 8. Means of total viable counts in stored mandazi.

\begin{tabular}{llll}
\hline Level (\% pumpkin flour) & Day 2 & Day 4 & Day 6 \\
\hline $1(0 \%)$ & $112 \pm 18 \mathrm{~b}^{*}$ & $350 \pm 129 \mathrm{~b}$ & $1075 \pm 95 \mathrm{e}$ \\
$2(5 \%)$ & $0.00 \mathrm{~d}$ & $117 \pm 17 \mathrm{c}$ & $2225 \pm 170 \mathrm{~d}$ \\
$3(20 \%)$ & $192 \pm 25 \mathrm{a}$ & $325 \pm 25 \mathrm{~b}$ & $4425 \pm 386 \mathrm{c}$ \\
$4(50 \%)$ & $50 \pm 8 \mathrm{c}$ & $750 \pm 129 \mathrm{a}$ & $12000 \pm 816 \mathrm{~b}$ \\
$5(95 \%)$ & $112 \pm 9 \mathrm{~b}$ & $640 \pm 33 \mathrm{a}$ & $21250 \pm 957 \mathrm{a}$ \\
$\mathrm{LSD}_{0.05}$ & 26.425 & 128.01 & 1004.7 \\
$P$-value & $<0.0001$ & $<0.0001$ & $<0.0001$ \\
\hline
\end{tabular}

*Means followed by the same letter within a column are not significantly different at $\alpha=0.05$.
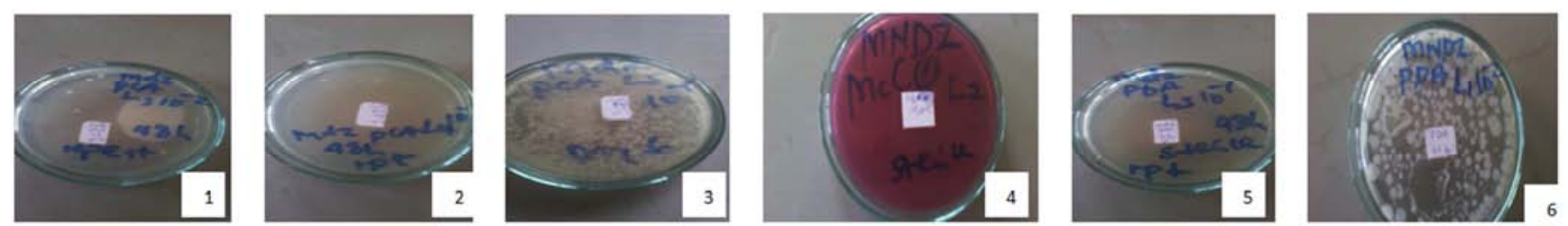

Figure 8. Appearance of PDA, PCA and MAC cultures of Mandazi. Plate 1: level 3 PCA 10-2 at 48 hrs, Plate 2: level 4 PCA 10-1 at 48 hrs, Plate 3: level 5 PCA $10^{-1}$ on day 6, Plate 4: level 2 MAC sterile at 48 hrs, Plate 5: level 3 PDA 10-1 sterile at 48 hrs, Plate 6: level 1 PDA $10^{-2}$ on day 6.

\subsubsection{Shelf-life of Bread}

The TVC for bread samples were monitored and results (Table 9) showed that levels 1, 2 and 3 had the longest shelflife of 6 days, while both levels 4 and 5 took four days before bacterial levels were beyond safe limits. Significant differences $(\mathrm{P}<0.05)$ in the number of cfu/g occurred for all days, and levels 4 and 5 consistently had higher bacterial counts. Observation of plates showed that PCA had creamy white, raised rough edged colonies, which were mucoid to touch, as well as round medium white colonies, which were identified as Gram positive cocci and Gram positive rods.

There was no growth in MacConkey agar and hence the bread was free of contamination by enteric bacteria (Plates 6 and 7, Figure 9). Plates with PDA showed no fungal growth up to day 4 for levels 1, 2 and 3, while levels 4 and 5 already had fungi growing by that time.

Table 9. Means of total viable counts in stored bread.

\begin{tabular}{lllll}
\hline $\begin{array}{l}\text { Level (\% } \\
\text { pumpkin flour) }\end{array}$ & Day 2 & Day 4 & Day 6 & Day 8 \\
\hline $1(0 \%)$ & $237 \pm 35 \mathrm{a}^{*}$ & $265 \pm 31 \mathrm{~b}$ & $412 \pm 15 \mathrm{~b}$ & $1275 \pm 221 \mathrm{c}$ \\
$2(5 \%)$ & $115 \pm 19 \mathrm{~b}$ & $272 \pm 15 \mathrm{~b}$ & $450 \pm 310 \mathrm{~b}$ & $1850 \pm 208 \mathrm{~b}$ \\
$3(20 \%)$ & $92 \pm 9 \mathrm{~b}$ & $195 \pm 12 \mathrm{c}$ & $317 \pm 17 \mathrm{~b}$ & $2150 \pm 129 \mathrm{a}$ \\
$4(50 \%)$ & $222 \pm 12 \mathrm{a}$ & $405 \pm 5 \mathrm{a}$ & $4675 \pm 17 \mathrm{a}$ & \\
$5(95 \%)$ & $100 \pm 8 \mathrm{~b}$ & $407 \pm 9 \mathrm{a}$ & $6500 \pm 2645 \mathrm{a}$ & \\
$\mathrm{LSD}_{0.05}$ & 26.047 & 24.319 & 1857.8 & 262.72 \\
$P$-value & $<0.0001$ & $<0.0001$ & $<0.0001$ & 0.0005 \\
\hline
\end{tabular}

*Means followed by the same letter within a column are not significantly different at $\alpha=0.05$.
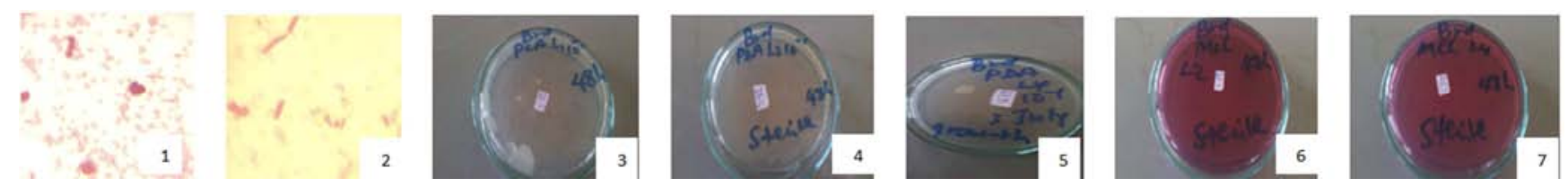

Figure 9. Appearance of PDA, PCA and MAC cultures of bread. Plate 1: Cocci, Plate 2: Bacilli, Plate 3: level 1 PCA 10-1 at 48 hrs, Plate 4: level 3 PDA 101 sterile at $48 \mathrm{hrs}$, Plate 5: level 4 PDA 10-1 on day 4, Plate 6: level 2 MAC sterile at 48 hrs, Plate 7: level 4 MAC sterile at 48 hrs.

\subsubsection{Shelf-life of Scones}

Microbial assessment of scones showed variation in terms of number of days each level of the product remained safe, whereby level 3 had the longest shelf-life of 22 days, 
followed by level 1 , while levels 4 and 5 had the shortest period of 6 days. Microbial levels were higher in level 3 at the beginning and the growth was noted to be slower compared to the other levels (Table 10). Significant differences $(P<0.0001)$ occurred in the number of $\mathrm{cfu} / \mathrm{g}$ for the various flour-blending levels at days two and four, with higher bacterial counts in levels 4 and 5. A significant difference $(P=0.0003)$ was also noted between levels 1 and 3 on day 20, with level 1 having much higher bacterial counts than level 3. Assessment of samples using the three different media revealed round, raised, white colonies, which were identified as Gram positive rods (Bacilli) in PCA, while PDA showed fungal growth, which occurred during the last days in each of the 5 levels of scones. MAC showed negative results hence no enteric bacteria were present in the pumpkin flourblended scones (Figure 10).

Table 10. Means of total viable counts in stored scones.

\begin{tabular}{|c|c|c|c|c|c|c|c|c|}
\hline Level & Day 2 & Day 4 & Day 6 & Day 8 & Day 18 & Day 20 & Day 22 & Day 24 \\
\hline $1(0 \%)$ & $107 \pm 22 d^{*}$ & $300 \pm 81 d$ & $317 \pm 17 \mathrm{c}$ & $387 \pm 25 a$ & $902 \pm 68 \mathrm{a}$ & $2025 \pm 125 a$ & & \\
\hline $2(5 \%)$ & $200 \pm 81 \mathrm{c}$ & $212 \pm 34 \mathrm{e}$ & $300 \pm 81 \mathrm{c}$ & $475 \pm 50 \mathrm{a}$ & $107 \pm 62 \mathrm{a}$ & & & \\
\hline $3(20 \%)$ & $302 \pm 5 b$ & $425 \pm 50 c$ & $525 \pm 52 \mathrm{bc}$ & $575 \pm 50 \mathrm{a}$ & $922 \pm 28 \mathrm{a}$ & $950 \pm 21 b$ & $990 \pm 21$ & $1200 \pm 163$ \\
\hline $4(50 \%)$ & $425 \pm 50 \mathrm{a}$ & $550 \pm 57 b$ & $705 \pm 25 b$ & $17225 \pm 2372 a$ & & & & \\
\hline $5(95 \%)$ & $90 \pm 21 d$ & $907 \pm 25 a$ & $5000 \pm 432 a$ & & & & & \\
\hline $\mathrm{LSD}_{0.05}$ & 69.115 & 72.577 & 296.88 & 18963 & 68.749 & 171.63 & & \\
\hline$P$-value & $<0.0001$ & $<0.0001$ & $<0.0001$ & 0.1853 & 0.4228 & 0.0003 & & \\
\hline
\end{tabular}

*Means followed by the same letter within a column are not significantly different at $\alpha=0.05$.
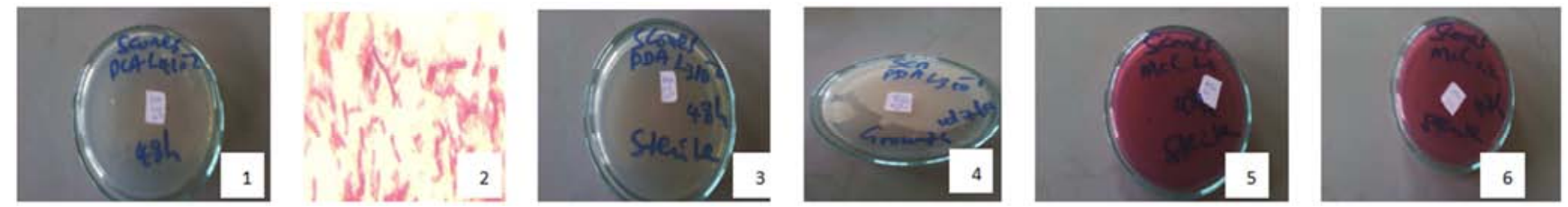

Figure 10. Appearance of scones cultures. Plate 1-level 4 PCA 10-2 at 48 hrs, Plate 2-Bacilli, Plate 3-level 3 PDA 10-2 sterile at 48 hrs, Plate 4- level 3 PDA 10-1 on day 22, Plate 5- level 1 MAC sterile at 48 hrs, Plate 6- level 2 MAC sterile at 48 hrs.

\subsubsection{Shelf-life of Chapatti}

Results on microbial assessment of chapatti showed that spoilage had already occurred by day two, with uncountable $\mathrm{cfu} / \mathrm{g}$. Figure 11 shows overgrowth of bacteria (uncountable colony forming units) in all the plates, which were observed as tiny white raised round colonies. Identification revealed
Gram positive short chains cocci (streptococci). There were also large raised white colonies identified as Gram positive rods (bacilli). There was also extensive fungal growth in PDA media, hence the products were discarded. There was no growth in MAC, implying that there was no contamination with enteric bacteria.
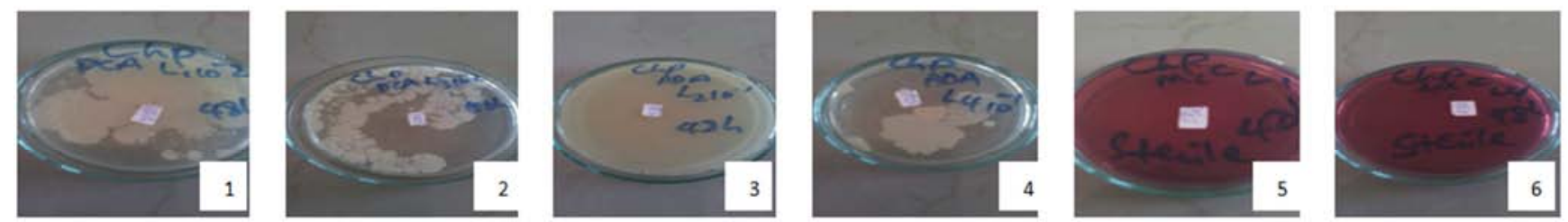

Figure 11. PDA, PCA and MAC cultures of chapatti at 48 hrs. Plate 1: level 1 PCA 10-2, Plate 2: level 3 PCA 10-2, Plate 3: level 2 PDA 10-1, Plate 4: level 4 PDA 10-1, Plate 5; level 1 MAC sterile, Plate 6: level 4 MAC sterile.

\subsubsection{Shelf-life of Porridge}

Results showed that on day two the bacteria had grown beyond limit and were not countable colonies (Figure 12). These were medium flat spreading, as well as round creamy white-coloured microorganisms identified as Gram positive rods (bacilli) and Gram positive cocco-bacilli. The PDA plates had an overgrowth of fungi, which indicated that the product was not fit for consumption by day two.
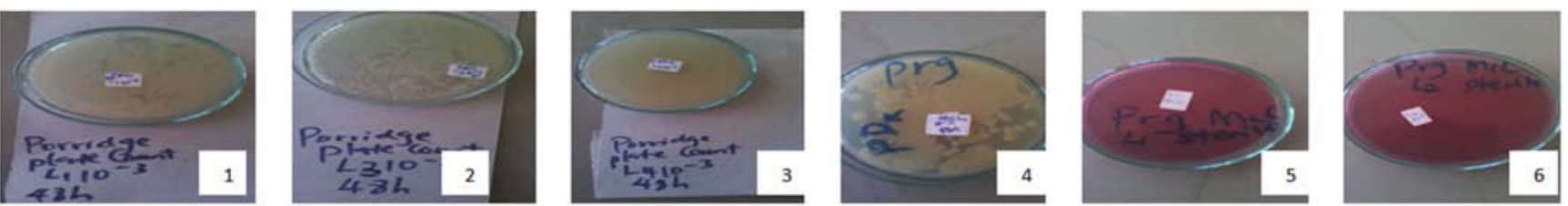

Figure 12. Appearance of PDA, PCA and MAC cultures of porridge at 48 hrs. Plate 1: level 1 PCA 10-3, Plate 2: level 3 PCA 10-2, Plate 3: level 4 PCA 10-3, Plate 4: level 4 PDA 10-2, Plates 5 and 6: levels 1 and 2 MAC sterile.

\subsubsection{Shelf-life of Irio}

Total viable counts for Irio on day two showed overgrown medium raised, white flat colonies in all the plates. These were identified as Gram positive long rods (bacilli) and Gram 
positive budding, spore forming cocco-bacilli (clostridium). PDA plates had extensive microbial growth identified as
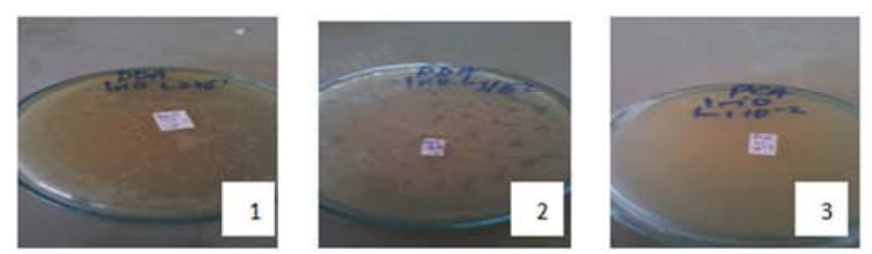

Gram positive budding rods, indicating that the food was already spoilt and not fit for consumption.
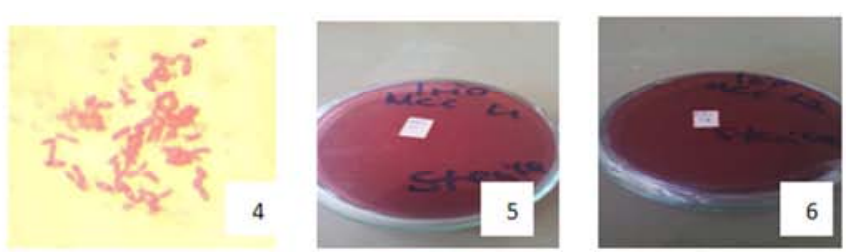

Figure 13. Appearance of PDA, PCA and MAC cultures of Irio at 48 hrs. Plate 1: level 2 PDA 10-1, Plate 2: level 3 PDA 10 $0^{-2}$ Plate 3: level 1 PCA 10-2, Plate 4: Bacilli, Plate 5 and 6: levels 1 and 2 MAC sterile.

\section{Discussion}

Results of microbial growth indicated that there was fast multiplication of microbes (both bacteria and fungi) in sliced fruit samples, given that day two was characterized by uncountable bacterial and fungal colonies in the plates. Microbial limits for ready-to-eat fresh fruits and vegetables have not been set [24]. It is clear that once pumpkin fruit is sliced, the shelf-life is drastically reduced; in this case from 6 months for whole fruit down to 4 days for fruit slices. A sliced fruit is therefore best consumed the same day since deterioration begins immediately after slicing. Apart from fungi which were abundant in sliced fruit and cause most of the spoilage, bacilli and cocci-bacilli bacteria were also present. Bacillus is present in most fruits and vegetables, leading to soft-rotting spoilage [5]. The present study showed that wrapping fruit slices played a role in preservation by reducing moisture loss rate and creating anaerobic environment that inhibited microbial growth.

Moisture content contributes a lot to food safety and shelflife. The higher the MC, the less the period in which a food will keep before spoiling. Moisture-rich foods are susceptible to attack by microbes, while low moisture levels slow down microbial growth. Moisture levels of $14 \%$ and above promote fungal growth, while lower moisture levels prevent spoilage [7]. Oven-dried (OED) flour had the shortest shelf stable period, compared to the ESD and OSD flour. The shorter shelf-life of OED flour (7 months), compared to OSD flour (10 months) was associated with high moisture content (15.15\%), although microbial load was highest in OSD flour. This was due to the fact that the OSD samples were directly exposed to the environment where they picked many microbes during drying. It has been reported that open airdrying, although cost-effective, is the poorest in terms of protection against dust, insects, microbes and nutrient loss [8, 25, 26]. Microbial assessment of the flours showed negative results for enteric bacteria, indicating that there was no contamination with enteric bacteria which are an indicator of fecal contamination, normally arising from unhygienic handling and cross contamination of food. Bacilli and streptococci bacteria were the microbes present in the flour; bacillus is a common microbe in most fruit and vegetable surfaces [5] from where it ends up in processed flour.

The results of the present study showed that ESD flour, which also had lowest MC, was superior to the others in terms of extraction rate. The extraction rate of flour has significant effect on flour quality [8]. Flour with highest extraction rate gives highest quality in terms of fibre and other nutrients like protein [16], but might give poor quality bread if used in high quantities during baking [27]. Azizi et al., [28] reported that flour characteristics, among them moisture, protein and crude fibre are all affected by flour extraction rates, whereby $\mathrm{MC}$ reduces with increasing extraction rate, while protein and crude fibre increases with increasing extraction rate [16]. Moisture reduces due to the presence of more fibre in the flour [29]. The increase of protein and fibre content at higher extraction rate is important for nutritional purposes and physiological effect of cellulose on the digestive system [16]. However, flour with higher extraction rate ends up having weaker bread baking quality since coarser particles are obtained, which affect gluten network of the dough, volume, texture and general quality of bread [27]. It has also been observed that gluten strength decreases with increasing extraction rate that reduce dough quality [30].

There was much less $\mathrm{MC}$ in cookies $(<10 \%)$, compared to the other products, which most likely prolonged shelf-life. Bread had the highest $\mathrm{MC}$, ranging from $32 \%-41 \%$, followed by cake and mandazi. Highest MC was for level 5 (41.75\%). Increased level of fibre in pumpkin flour increases $\mathrm{MC}$ in breads due to higher water absorption capacity of the fibre [31]. Moisture content is an important determinant of quality and stability of a processed food product. Microbial activity of food is favoured by moisture availability, and moisturerich foods are susceptible to microbial attack, rotting and damage. Low moisture-rich foods slow down growth of microorganisms, and hence the need for analysis and control of food moisture.

Cookies had a relatively longer shelf-life and were able to stay safe for slightly over two months before getting spoilt. This response was attributed to their low MC, which reduces water activity in the product, thereby assuring microbial stability in a product [32]. Cookies also had a desirable long mould-free period. Microbes in cookies were identified as bacilli and staphylococci. Bacillus cereus is common in most farm produce [5] from where it finds its way into finished products. Bacillus contamination mostly originates from raw ingredients [23]. Bacillus cereus is a food-borne bacterial pathogen, and when over $10^{4} \mathrm{cfu} / \mathrm{g}$, food is considered unsatisfactory. Some strains of $B$. cereus may cause food poisoning with an infective dose as low as $10^{3}-10^{4} \mathrm{cfu} / \mathrm{g}$, and hence a limit of $10^{3}$ was used to indicate product safety. Staphylococci bacteria are normally from food handlers since they are present but not harmful on human skin, nasal passage and throat. Nonetheless, they can cause food 
poisoning. Fortunately, they are normally destroyed by normal cooking procedures. When not all are destroyed, however, prolonged storage of products without refrigeration allows them to grow and form toxins [24].

Cookies had a relatively long shelf-life and were able to keep safe for slightly over two months before expiring due to their low moisture content (less than 10\%) which inhibited microbial growth. Cookies have outstanding microbial stability and are able to safely keep for slightly over two months on the shelf. Cookies do not have a high microbiological risk since the water activity levels are below the minimum levels required for microbial growth. The shelf stable pumpkin blended cookies should translate to great economic importance to manufacturers since less wastage will occur from production to consumption. The product is likely to be profitable if adopted into local markets. Cakes took relatively shorter time before getting spoilt compared to cookies and this was attributed to the higher MC (19\%-33\%) that favoured microbes. Bacilli bacteria are the existing spoilage bacteria in cake, similar to cookies. They are present in most uncooked foods and survive baking or cooking temperatures and grow in finished product provided the temperature remains above refrigeration level [32].

Mandazi had a short shelf-life of 4 days, which was increased from 2 days by addition of lemon juice and zest during product development. This short shelf-life was attributed to slightly higher MC $(26 \%, 23 \%$ and $26 \%$, compared to cake's $19.5 \%, 24 \%$ and $20 \%$ at levels 1,2 and 3 , respectively). The slight difference alone may not justify such big difference in shelf-life, from 4 days for mandazi to 10 days for cake. Betts et al., [32] indicated that apart from water activity in a food, ingredients such as fat and sugar in cake bind water, thus inhibiting microbial growth.

Owing to high MC in bread, a shorter shelf-life of 6 days resulted for levels 1, 2 and 3, and 4 days for levels 4 and 5 . Microbial growth largely depended on MC in the product. Bacilli and cocci bacteria present in bread were reported in a study by Satchanska et al. [33], who isolated and obtained motile cocci, as well as short and long-sized rods, and concluded that bacillus and micrococcus are among the pathogens present in bread at spoilage stage. A similar study using bread samples collected from different shops in the local market of Jaffna reported fungal growth on bread samples from day 4 [34].

Moisture content, especially level 3 in scones did not affect microbial growth. This result was attributed to the fact that water evaporates from food, hence affecting water activity that contributes to control of microorganisms. Water evaporation is not the only factor associated with microbial food safety, but addition of ingredients such as fat, sugar and salt play a major role in binding water in food $[32,35]$. Thus in the scones, despite increasing $\mathrm{MC}$ with increase in pumpkin flour, level 3 might have had the added fats (margarine and butter) and sugar control microbial growth.

Pumpkin flour levels in the three home-based products (Chapatti, porridge and Irio) did not have any impact on shelf-life in that all the 5 levels deteriorated before the first microbial assessment could be done and were no longer safe after 1-day post-production. Predominance of Bacillus species in cooked food is associated with latent spores in raw materials, which may survive cooking to multiply under favourable conditions [5]. Porridge deteriorated in 1 day due to its high moisture, and no components in the recipe were able to bind the available water to inhibit growth of microorganisms. Bacteria in porridge were the common Bacilli, alongside lactobacilli which most likely originated from milk in the recipe used.

\section{Conclusions and Recommendations}

Slicing pumpkin fruit drastically reduces its shelf-life and the slices are only safe to consume within the first 3 to 4 days after slicing. Preservation of pumpkin fruits by drying is a superb way of preventing postharvest loss when there is a lot to take care of either by selling or consuming before spoilage. Pumpkin fruit only stores longer if completely free of even the slightest bruise, which eventually cause rotting within the first few weeks after harvest. This study recommends creation of awareness among farmers on importance of solar driers as a means of pumpkin fruit flour preservation. Moisture content in market-targeted products increases with increasing pumpkin flour levels. For cake, flour levels 1, 2 and 3 remain safe for up to 10 days. Cake that contains no commercial preservatives stands a good chance of getting into the market, especially in fast food context. The 6 days of shelf stable fortified bread is a relatively workable period, especially when the product turnover is high in the market. Adoption of pumpkin flourfortified bread into the local market and fast snack food shops is recommended. The added fats and sugar in scones contributes to their keeping quality and preservation. A period of 8 days' shelf stability is feasible for marketing pumpkin flour-blended scones in local markets. The short microbial stability of mandazi, which closely share MC with cake that generally took 10 days, is as a result of the mandazi components, which do not have a water binding effect as is the case for cake. It is, therefore, recommended to consider use of permitted food preservatives when adopting this product for the market to assure product safety and reduce economic losses to the producer. Chapatti has very low microbial stability and only keeps safe on the first day of production after which it is not be safe for consumption. The desirable pumpkin blended chapatti is highly acceptable for adoption at household or restaurant level, which ensures same day consumption. Porridge is only able to keep fresh and safe for consumption at day 1 of production, hence it remains a desirable home-based food. Pumpkin blended Irio is an appealing and nutritious food adoptable for household consumption to improve nutrition and should be consumed within the same day of preparation. Shelf-life of marketable products reduces with increasing pumpkin flour levels. Too much pumpkin flour does not produce consumer-acceptable products hence medium level is recommended to balance shelf-life and consumer acceptability. Fortification of bakery products with up to $20 \%$ pumpkin flour produces longest shelf-life. There is no contamination with enteric bacteria during preparation and handling of all the products and hence developed recipes have high feasibility of yielding consumer- 
safe products.

\section{Acknowledgements}

We acknowledge the Kenya Agricultural Productivity and Agribusiness Project (KAPACGS/CN2010/RCNO1, KAPAP CGS/CN2010/HC/RCNO03) and the National Commission for Science, Technology and Innovation (NACOSTI/RCD/ST\&I5thCALLPHD/173) for providing grants which made this research possible.

\section{References}

[1] Lequeu, J., Fanconnier, M. L., Chammai, A., Bronner, R. and Blee, E. (2008) Formation of plant cuticle: Evidence of the occurrence of the peroxygenase pathway. Plant Journal, 36, 155-164.

[2] O'connor-Shaw, R. E., Roberts, R. and Ford, A. L. (1996) changes in sensory quality of sterile cantaloupe dices stored in controlled atmosphere. J Food Sci, 61, 847-851.

[3] Saranraj, P., Stella, D. and Reetha, D. (2012) Microbiological spoilage of vegetables and its control measures: A review. Int. J. Natur. Prod. Sci., 2(2), 1-12.

[4] Masarirambi M. T., Mavuso V, Songwe V. D., Nkambule T. P. and Mhazo, N. (2010) Indigenous post-harvest handling and processing of traditional vegetables in Swaziland: A review. Afr J Agric Res, 5(24), 3333-3341.

[5] Barth, M., Hankinson, T. R., Zhuang, H. and Breidt, F. (2009) Microbial spoilage of fruits and vegetables, P. 135-183. In: W. H. Sperber, M. P. Poyle (eds.). Compendium of the Microbiological Spoilage of Foods and Beverages, Food Microbiology and Food Safety, DOI 10.1007/978-1-4419-08261_6, (CSpringer Science+Business Media, LLC 2009.

[6] Onyango, M. O. A., Habwe, F. O. and Walingo, K. M. (2008) Food processing and preparation technologies for sustainable utilization of African indigenous vegetables for nutrition security and wealth creation in Kenya. International Union of Food Science and Technology. Chapter 13, 1-9.

[7] Hoseney, R. C. (1994) Principles of Cereal Science and Technology. $2^{\text {nd }}$ Edition. American Association of Cereal Chemistry Inc., St Paul, Minnesota; USA.

[8] Kiharason, J. W. Isutsa, D. K. and Ngoda, P. N. (2017a) Effect of drying method on nutrient integrity of selected components of pumpkin (Cucurbita moschata Duch.) fruit flour. ARPN Journal of Agricultural and Biological Sciences, 12(3), 110-116.

[9] Mnzava, N. and Mbewe, J. E. (1997) African traditional vegetables. Selecting dual-purpose local pumpkins Cucurbita moschata (Duch. ex Lam.). Report.

[10] Ondigi, A. N., Toili, W. W., Afisihi, S. M. and Stanley, O. O. (2008). Comparative analysis of production practices and utilization of pumpkins (Curcubita pepo and Curcubita maxima) by smallholder farmers in the Lake Victoria Basin, East Africa. Afr J Env Sci Technol, 2(9), 296-304.

[11] Dar, A. H., Sofi, S. A. and Rafiq, S. (2017). Pumpkin the functional and therapeutic ingredient: A review. International Journal of Food Science and Nutrition; 2 (6), 165-170.
[12] Hamisy, W. C., Makundi, A. H., Marandu, D. and Nkya, M. J. (2002) Evaluation of five accessions of Cucurbita maxima collected from different ecological zones in Tanzania. The Second International Workshop on Plant Genetic Resources and Biotechnology Report, Arusha, Tanzania, p. 6-10. http://apps.fao.org/page/collections?subset=agriculture.

[13] Barkema, A. (1993) Reaching consumers in the twenty first century: The short way around the barn. Amer J Agr Econ, 75(5), 1126-1131.

[14] Sedibe, M. H., Pisa, P. T., Feely, A. B., Pedro, T. M., Kahn, K. and Norris, S. A. (2018) Dietary habits and eating practices and their association with overweight and obesity in rural and urban black South African adolescents. Journal of Nutrients, (10), 145; doi: $10.3390 /$ nu10020145.

[15] El-Demery, M. E. (2011) Evaluation of physical-chemical properties of toast breads fortified with pumpkin (C. moschata) flour. The $6^{\text {th }}$ Arab and $3^{\text {rd }}$ International Annual Scientific Conference on Development of Higher Specific Education Programs in Egypt and the Arab World in Light of Knowledge Era Requirements. Faculty of Specific Education, Mansoura University, Egypt. 13-14 ${ }^{\text {th }}$ April, 2011.

[16] Kiharason, J. W., Isutsa, D. K. and Ngoda, P. N. (2017b). Nutritive value of bakery products from wheat and pumpkin composite flour. Global J. Biosci and Biotech, 6 (1), 96-102.

[17] Fellows, P. J. (2009) Food Processing Technology: Principles and Practice ( $3{ }^{\text {rd }}$ Edition). Woodhead Publishing House.

[18] Djutin, K. E. (1991) Pumpkin: Nutritional properties. Potatoes and Vegetables 3, 25-26.

[19] Roessler, P. F. and Ballenger, M. C. (2006) Contamination of and unpreserved semi soft baked cookie with a Xerophikic, and Aspergillus species. J Food Prod, 59, 1055-1060.

[20] Banwart, G. J. (2004) Basic Food Microbiology. A Westport Publication. Pp. 505-544.

[21] Sofos, J. N and F. Busta. (1991) Antimicrobial activity of sorbate. J Food Prot, 44, 614-621.

[22] Needham, R., James William, Williams, J., Beales, N., Voysey, P. and Magan, N. (2004) Early detection and differentiation of spoilage of bakery products. Sensors and Actuators B 106, 20-23.

[23] Bailey, C. P. and Holy, A. V. (1993). Bacillus spore contamination associated with commercial bread manufacture. Food Microbiology, 10, 287-294.

[24] ICMSF (2001) Guidelines for the microbiological examination of ready-to-eat foods. International Commission on Microbiological Specifications for Foods (ICMSF), December, 2001.

[25] Eze, J. I. and Chibuzor, E. E. (2008) Evaluation of the drying efficiency of solar cabinet dryer using okra and tomato. Niger J Solar Energy, 19 (1), 25-33.

[26] Anyanwu C. N. and Okonkwo, W. I. (2008) Experimental determination of the drying rate of chilly yellow pepper (Capsicum anuum). Niger J. Solar Energy, 19(1), 18-24.

[27] Kiharason, J. W., Isutsa, D. K. and Ngoda, P. N. 2017c. Evaluation of sensory acceptability of bakery products prepared from wheat and pumpkin composite flour. International Journal of Science and Nature, 8(1), 1-7. 
[28] Azizi, M. H., Sayeddin, S. M. and Payghambardoost, S. H. (2006) effect of extraction rate on flour composition, dough rheological characteristics and quality of flat bread. J Agric Technol, 8, 323-330.

[29] Hosseini, G. H. S. H., Seyedain, A. S. M. and Kashainejad, M. (2017) Physico-chemical, textural and sensory evaluation of sponge cake supplemented with pumpkin flour. International Food Research Journal, 25(2), 854-860.

[30] Orth, R. A. and Mander, K. C. (1975) Effect of milling yield on flour composition and breadmaking quality. American Association of Cereal Chemists, Inc.

[31] See, E. F., Wan Nadiah, W. A. and Noor Aziah, A. A. (2007) Physic-chemical and sensory evaluation of breads supplemented with pumpkin flour. ASEAN Food J., 14 (2), 123-130.

[32] Betts, G., Cook, S., Mclean, B., Betts, R., Sharpe, T. and walker, S. (2006) Scientific Review of the Microbiological Risks Associated with Reductions in Fat and Added Sugar in Foods. Funded by the Food Standards Agency. http://www.n:\2006\MB \GD\kt06224 (final).

[33] Satchanska, G., Doychera, A. and Panayotova, S. (2012) Microbiological analysis of flour and whole grain bread and biochemical identification of bacterial isolates. Iubmb \& Febs, Sevilla 2012.

[34] Ravimannan, N., Sevvel, P. and Saarutharshan, S. (2016) Study on fungi associated with spoilage of bread. Int. J. Adv. Res. Biol. Sci., 3 (4), 165-167.

[35] Garcia-Segovia, P., Moreno, A., Benitez, L. R., Logrono, M. A., Fonseca, J. G. and Martinez-Monzo, J. (2017) Effect of replacement of wheat flour by a composite mix flour in sponge cakes. Journal of Culinary Science \& Technology; 15:2, 89-100, DOI: 10.1080/15428052.2016.1220340. 